\title{
Perbaikan Tata Letak Fasilitas Gudang Dengan Pendekatan Dedicated Storage Pada Gudang Distribusi Barang Jadi Industri Makanan Ringan
}

\section{Layout Improvement with Dedicated Storage Approach in Food and Baverage Product Warehouse}

\author{
Yuyut Tri Prasetyo*, Ahmad Fatih Fudhla \\ Program Study Teknik Industri, Fakultas Teknik, Universitas Maarif Hasyim Latif \\ Raya Ngelom Megare, Taman, Sidoarjo, 61257, Indonesia \\ Email: yuyut.tri.prasetyo@gmail.com,fatih_fudhla@dosen.umaha.ac.id
}

\begin{abstract}
ABSTRAK
Gudang Distribusi pada studi kasus ini memiliki kapasitas penyimpanan sebesar 11.600 palet posisi. Pengaturan penyimpanan menggunakan metode randomized storage dimana produk yang sama di tempatkan di lokasi yang berbeda secara acak. Metode penempatan ini menyebabkan tingginya waktu proses baik dalam mekanisme penerimaan maupun pengeluaran barang. Metode dedicated storage digunakan untuk memperbaiki permasalahan ini. Klasifikasi produk dilakukan dengan mempertimbangkan karakteristik produk, jenis dan berat produk. Setelah di lakukan perbaikan, waktu proses dapat dikurangi hingga 30.0\% untuk mekanisme penerimaan dan 27.6\% untuk mekanisme pengeluaran barang. Presentase klasifikasi produk yang di dapatkan kategori A(superpareto) 78,72\%, kategori B (fast moving) 16,27\%, kategori C (medium moving) 4,49\% dan kategori D (slow moving) $0,52 \%$.
\end{abstract}

Kata Kunci: dedicated storage, inbound outbound, tata letak, throughput

\begin{abstract}
The distribution warehouse in this case study has a storage capacity of 11,600 position pallets. The storage arrangement uses the randomized storage method where the same product is randomly placed in different locations. This placement method causes high processing time both in the mechanism of receiving and releasing goods. The dedicated storage method is used to fix this problem. Product classification is carried out by considering the characteristics of the product, the type and weight of the product. After repairs are made, processing time can be reduced by up to $30.0 \%$ for the receiving mechanism and $27.6 \%$ for the goods release mechanism. The percentage of product classifications obtained was category A (superpareto) $78.72 \%$, category B (fast moving) $16.27 \%$, category C (medium moving) $4.49 \%$ and category D (slow moving) $0.52 \%$.
\end{abstract}

Keywords: dedicated storage, inbound outbound, layout, throughput

\section{Pendahuluan}

PT. DC merupakan perusahaan yang beroperasi memproduksi makanan ringan. Perusahaan tersebut memiliki gudang distribusi tersebar di seluruh wilayah Indonesia. Gudang pusat distribusi Gresik merupakan gudang terbesar diantara gudang PT. DC lainnya. Gudang yang memiliki luas 9720 M2 dengan kapasitas penyimpanan 11.600 palet posisi ini telah menjalankan Sistem Manajemen Pergudangan dengan di dukung tipe penyimpanan Selective Pallet Racking (SPR). Meskipun demikian, pengaturan penyimpanan masih dilakukan secara acak. Item Produk yang sama diletakkan pada lokasi yang terpencar. Tidak ada lokasi tetap. Cara penempatan ini menyebabkan waktu proses bongkar muat yang lama. Dalam proses penerimaan (inbound) membutuhkan waktu 3.37 menit dan proses pengeluaran (outbound) 3.33 menit. Keduanya masih jauh dari rata-rata target kinerja perusahaan sebesar 2.5 menit.

Pada penelitian ini metode dedicated storage digunakan untuk perbaikan sistem. Pengaplikasian ini di harapkan bisa menurunkan waktu proses bongkar muat dalam proses inbound maupun outbound.

\section{Metode Penelitian}

Gudang 


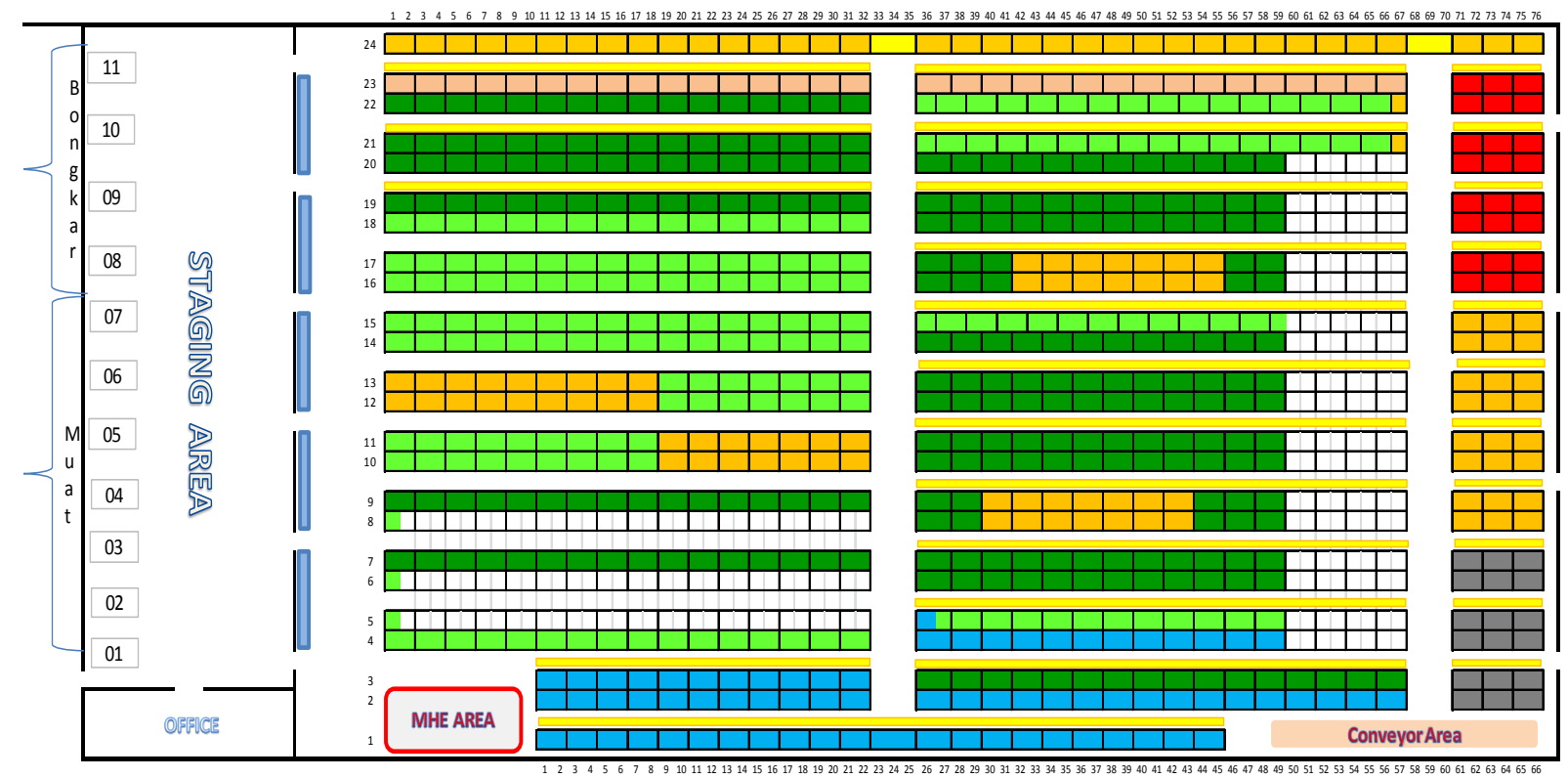

Gambar 1. Tata letak gudang kondisi awal

Menurut Warman (2012), gudang adalah bangunan yang difungsikan untuk penyimpanan barang. Barang-barang yang di simpan di dalam gudang dapat berupa apa saja, dari mulai bahan baku, barang yang sedang diproses, barang jadi, atau barang pendukung fungsi produksi (misalkan sparepart mesin). sedangkan menurut Wignjosoebroto (2009) gudang adalah tempat penyimpanan sementara barang baik yang masih berupa bahan baku, barang setengah jadi, maupun barang jadi.

\section{Tata letak atau Layout}

Tata letak atau layout pada suatu proses bisa memiliki dampak strategis karena sangat berpengaruh pada tingkat efesiensi sebuah proses. Penataan posisi fasilitas yang baik dan efektif dapat membantu perusahaan dalam mencapai menurunkan biaya dan meningkatan responsivitas. (Bandyopadhyay, 2019).

Menurut Muther \& Webster (2009), tata letak pabrik adalah "mekanisme penataan fasilitas fisik perusahaan guna mendapatkan sistem aliran yang efektif dan efisien". Menurut Sritomo Wignjosoebroto (2009), perencanaan tata letak fasilitas adalah "tata cara pengaturan fasilitas-fasilitas pabrik guna menunjang kelancaran produksi".

\section{Metode Penyimpanan Gudang}

Pada penyimpanan barang di gudang ada beberapa metode yang di tentukan, menurut Moran (Moran, 2017a) ada beberapa metode yang dapat digunakan untuk menyimpan barang antara lain:

\section{Metode Dedicate Storage}

Sebagaimana makna "dedicated", pada metode ini setiap ruangan/fasilitas penyimpanan dibagi dan didedikasikan khusus untuk produk tertentu. (Fumi et al., 2013)

\section{Metode Randomized Storage}

Metode penyimpanan ini berkebalikan dari metode dedicated storage. Barang datang disimpan pada tempat secara acak dengan mempertimbangkan jarak terdekat dengan pintu loading unloading didahulukan .(Moran, 2017b)

\section{Metode Class Based Storage.}

Metode ini adalah kompromi antara dua motode penyimpanan di atas. Penyimpanan dilakukan dengan mengelompokkan kelas tertentu. Fasilitas terdedikasikan berdasarkan kelas atau kelompok tersebut. Dan pada masing-masing kelas penempatan penyimpanan dilakukan secara random. Pembagian kelas berdasarkan nilai rasio antara Troughput (T) dan Storage (S). (Ekren et al., 2015)

\section{Metode Shared Storage Location}

Metode penyimpanan ini bersifat flexible, informasi kedatangan dan jumlah barang yang akan datang harus diketahui beberapa waktu seelumnya.(Yang et al., 2015)

Menurut Moran (Moran, 2017b), metode dedicated storage adalah mekanisme penyimpanan yang sudah tertentu dan tetap karena lokasi untuk tiap barang sudah ditentukan khusus untuk produk tersebut. Kebutuhan ruang untuk setiap produk harus bisa dicukupi oleh total alokasi ruang penyimpanan (Moran, 2017a). Jika produk yang akan disimpan lebih dari satu jenis, maka total ruang penyimpanan yang diperlukan adalah kumulatif dari kebutuhan penyimpanan maksimal dari setiap produk (Sentia et al., 2017). 
Tabel 1. Kebutuhan bin/slot per kategori produk.

\begin{tabular}{cc}
\hline Kategori & Kebutuhan Palet \\
\hline A & 9.139 \\
B & 1.894 \\
C & 548 \\
D & 103 \\
Total & 11.684 \\
\hline
\end{tabular}

Tabel 2. Kebutuhan bin/slot per kategori produk.

\begin{tabular}{|c|c|c|c|c|c|c|c|}
\hline No & $\begin{array}{l}\text { Nomor } \\
\text { Material }\end{array}$ & $\begin{array}{l}\text { Rerata masuk } \\
\quad \text { (inCRI) }\end{array}$ & $\begin{array}{l}\text { Rerata keluar } \\
\quad \text { (inCRI) }\end{array}$ & $\begin{array}{c}\text { Total } \\
\text { Throughput }\end{array}$ & $\begin{array}{l}\text { Rerata Masuk } \\
\quad \text { (inPLI) }\end{array}$ & $\begin{array}{l}\text { Rerata keluar } \\
\quad \text { (inPLI) }\end{array}$ & $\begin{array}{c}\text { Total } \\
\text { Throughput }\end{array}$ \\
\hline 1 & 9000000152 & 66,828 & 68,838 & 135,666 & 557 & 574 & 1,131 \\
\hline 2 & 9000000111 & 35,016 & 12,016 & 47,032 & 700 & 240 & 940 \\
\hline 3 & 9000001740 & 33,889 & 13,721 & 47,610 & 605 & 245 & 850 \\
\hline 4 & 9000001326 & 19,594 & 27,499 & 47,093 & 327 & 458 & 785 \\
\hline 5 & 9000001463 & 23,134 & 23,668 & 46,802 & 361 & 370 & 731 \\
\hline 6 & 9000001212 & 18,405 & 18,756 & 37,161 & 329 & 335 & 664 \\
\hline 7 & 9000000891 & 13,207 & 14,482 & 27,689 & 236 & 259 & 495 \\
\hline 8 & 9000001868 & 16,361 & 15,476 & 31,837 & 205 & 193 & 398 \\
\hline 9 & 9000001690 & 13,486 & 11,593 & 25,079 & 211 & 181 & 392 \\
\hline 10 & 9000001742 & 11,098 & 10,285 & 21,383 & 198 & 184 & 382 \\
\hline 11 & 9000001562 & 15,348 & 3,253 & 18,601 & 274 & 58 & 332 \\
\hline 12 & 9000001545 & 9,917 & 11,136 & 21,053 & 155 & 174 & 329 \\
\hline 13 & 9000001854 & 5,174 & 5,185 & 10,359 & 144 & 144 & 288 \\
\hline 14 & 9000001428 & 8,360 & 7,805 & 16,165 & 139 & 130 & 269 \\
\hline 15 & 9000000164 & 2,202 & 12,856 & 15,058 & 39 & 230 & 269 \\
\hline 16 & 9000000612 & 20,151 & 18,378 & 38,529 & 129 & 118 & 247 \\
\hline 17 & 9000000110 & 7,608 & 7,918 & 15,526 & 119 & 124 & 243 \\
\hline 18 & 9000000750 & 3,639 & 4,901 & 8,540 & 101 & 136 & 237 \\
\hline 19 & 9000000176 & 11,866 & 11,985 & 23,851 & 99 & 100 & 199 \\
\hline 20 & 9000001720 & 3,153 & 3,151 & 6,304 & 90 & 90 & 180 \\
\hline
\end{tabular}

Retnowati et al (Retnowati \& Fudhla, 2013) melakukan perbaikan tata letak fasilitas dengan pendekatan Linear Mix Integer Programming.Ginanjar, Reza (Ginanjar, 2018) mengaplikasikan Dedicated Storage pada gudang produk keramik dan mampu mengurangi biaya material handling sebesar 22,61\%. Abyadl, Qulubul (Abyadl, 2017) pada penelitiannya juga berhasil menurunkan waktu tempuh dan biaya material handling. Sentia Prima et al (Sentia et al., 2017) mengaplikasikan metode dedicated storage pada gudang bahan jadi dengan mempertimbangkan karakteristik produk, luasan area dan nilai throughput. Hidayat, Mirza Taufik (Hidayat, 2016) mampu menentukan secara tepat kapasitas blok penyimpanan yang dibutuhkan sehingga memudahkan operator secara efisien menyimpan produk. Septiani et al (Septiani et al., 2020) dan Muharni et al (Muharni et al., 2019) merancang tata letak gudang pendekatan descrete event simulation

\section{Hasil dan Pembahasan}

Kondisi gudang sebelum perbaikan

Layout pengkategorian kondisi awal pada gudang diperlihatkan pada Gambar 1. Pada tata letak kondisi sebelum perbaikan untuk penempatan ketika kondisi slot/bin dalam kondisi kosong maka barang dengan kategori apapun akan di arahkan oleh sistem kelokasi slot tersebut, tanpa mempertimbangkan waktu tempuhnya. Dengan kata lain produk tanpa di bedakan berdasarkan klasifikasi nya bisa menempati setiap slot ruang yang kosong. Hal ini bisa diartikan bahwa pada kondisi sekarang masih belum ada aturan baku untuk penempatan produk. Hal ini berdampak pada munculnya total jarak tempuh yang cukup besar dan tidak terprediksi 
secara akurat baik pada saat proses inbound dan outbound.

Penempatan produk dengan metode dedicated storage.

\section{Menentukan klasifikasi produk berdasarkan kecepatan penjualan.}

selanjutnya adalah mementukan kebutuh ruang penyimpanan untuk setiap material produk. Dasar perhitungannya adalah sebagaimana ditunjukkan pada persamaan 2 berikut:

Kebutuhan ruang $=$

\% Total kontribusi produk×total kapasitas Gudang

(2)



Gambar 2. Area Pembagian Tata letak Usulan (Area produk kategori A, B, C dan D)

Dalam tahap ini yang di lakukan adalah menentukan klasifikasi produk berdasarkan kontribusi penjualan nya setiap produk. Hal ini bertujuan untuk membagi setiap jenis produk dalam menentukan kategori apakah masuk dalam superpareto, fast moving, medium moving atau slow moving. Dalam data ini setiap kategori di wakilkan dengan kode huruf masing- masing adalah A untuk superpareto, B untuk fast moving, $\mathrm{C}$ untuk medium moving dan D untuk slow moving.

Pada proses ini dasar penghitungan nya adalah sebagaimana ditunjukkan pada persamaan 1 berikut:

Kontribusi jual produk $=\frac{\sum \text { penjualan produk }}{\sum \text { penjualan semua produk }} \times 100 \%$

Jika sudah di dapat nilai kontribusi jual per item produk maka dalam menentukan klasifikasi nya dapat di tentukan dengan mengetahui dari nilain total kontribusi jual nya yaitu: apabila nilai total kontribusi $\leq 80 \%$ maka masuk dalam kategori A (superpareto), nilai total kontribusi $>80 \%$ atau $\leq 95 \%$ masuk kategori B (Fast moving), jika nilai totak kontribusi $>95 \%$ atau $\leq 99,5 \%$ maka masuk dalam kategori $\mathrm{C}$ (medium moving) dan $\mathrm{D}$ (slow moving).

\section{Menghitung kebutuhan ruang penyimpanan bin/slot per produk}

Setelah tahap menentukan kelas produk berdasarkan total kontribusi jual nya maka pada proses
Maka di dapatkan hasil kebutuhan ruang slot per kategori produk sebagaimana ditunjukkan pada rekapitulasi Tabel 1.

Dari tabel di atas dapat di ketahui kebutuhan slot/bin penyimpanan per kategori produk adalah untuk kategori A (superpareto) sebesar 9139 palet posisi, kategori B (Fast moving) sebesar 1894 palet posisi, kategori C (Medium moving) sebesar 548 palet posisi, kategori D (Slow moving) sebesar 103 palet posisi dengan total kebutuhan slot adalah 11684 palet posisi.

\section{Menghitung Throughput dan perangkingan produk}

Dari tabel di atas diperoleh nilai throughput tertinggi pada item 9000000152 sebesar 1.131 aktivitas dalam rata - rata perbulannya, artinya pada saat penentuan bin/slot penempatan item tersebut di tempatkan pada racking terdekat dengan mempertimbangkan jarak tempuh tercepat terhadap lokasi I/O. Sedangkan dengan nilai throughput semakin kecil maka lokasi penempatan nya semakin menjauh dari titik lokasi I/O,sampai dengan material yang paling rendah aktifitas nya. disamping itu dalam menentukan penempatan ini aspek- aspek lain seperti klasifikasi produk, jenis produk, berat dan karakteristik produk harus dipertimbangkan.

\section{Usulan Perbaikan Tata Letak Gudang.}


Tata letak usulan ditunjukkan pada gambar 2 . Kebutuhan palet posisi penyimpanan di hitung berdasarkan prosentase throughput kategori. Penyimpanan terlihat lebih rapih, utilisasi dapat dihitung dan jarak tempuh yang di hasilkan lebih cepat sehingga bisa meningkatkan produktifitas.

1. Rata-rata waktu tempuh inbound.

Berikut penghitungan rata - rata waktu tempuh usulan per satu trip:

$$
\begin{aligned}
& A T T_{i n}=\frac{\sum_{i}\left(A T T_{i n_{i}} \times V l_{i}\right)}{\sum_{i} \text { Vol }_{i}} \\
& =\frac{((2.08 \times 78.72)+(3.19 \times 16.27)+(4.02 \times 4.49)+(4.67 \times 0.52))}{100} \\
& =(164.02+51.84+18.06+2.43) / 100 \\
& =236.35 / 100 \\
& =2.36 \text { menit. } \\
& \text { Dimana: } \text { ATT }_{\text {in }}=\text { Average Trip Time Inbound }
\end{aligned}
$$

2. Rata-rata waktu tempuh outbound

Berikut penghitungan rata - rata waktu tempuh usulan per satu trip:

$$
A T T_{\text {out }}=\frac{\sum_{i}\left(\text { ATT }_{\text {out }_{i}} \times \operatorname{Vol}_{i}\right)}{\sum_{i} \operatorname{Vol}_{i}}
$$

$$
\begin{aligned}
& =\frac{((2.13 \times 78.72)+(3.19 \times 16.27)+(4.14 \times 4.49)+(4.87 \times 0.52))}{100} \\
& =(167.76+51.90+18.59+2.52) / 100 \\
& =240,77 / 100 \\
& =2,41 \text { menit. } \\
& \text { Dimana: } \text { ATT }_{\text {out }}=\text { Average trip Time outbond }
\end{aligned}
$$

3. Perbandingan waktu tempuh kondisi sekarang dengan usulan

Tabel 3. Perbandingan waktu proses kondisi awal dengan usulan

\begin{tabular}{lcccc}
\hline Proses & \multicolumn{2}{c}{$\begin{array}{c}\text { Rata-rata waktu } \\
\text { per trip (menit) } \\
\text { kondisi } \\
\text { awal }\end{array}$} & $\begin{array}{c}\text { kondisi } \\
\text { usulan }\end{array}$ & perbaikan \\
(menit) & Persentase \\
\hline Inbound & 3.37 & 2.36 & 1.01 & $30.0 \%$ \\
outbound & 3.33 & 2.41 & 0.92 & $27.6 \%$ \\
\hline
\end{tabular}

Pada tabel perbandingan di atas terdapat penurunan antara waktu tempuh sebelum dan usulan di masing-masing proses, yaitu sebesar 30\% atau 1,01 menit/trip pada proses penerimaan (inbound) dan pada proses pengeluaran (outbound) turun sebesar 0,92 menit/trip atau $27.6 \%$.

\section{Kesimpulan}

Hasil penerapan dalam usulan perbaikan dengan metode dedicate storage menghasilkan penyelesaian masalah antara lain, Prosentase pembagian volume klasifikasi produk terbagi atas macam kategori yaitu, kategori $\mathrm{A}($ superpareto) sebesar 78,72\%, B(fast moving) 16,27\%, C(medium moving) 4,49\% dan C(slow moving) $0,52 \%$ dari total kapasitas penyimpanan 11.600 palet posisi. Dari hasil analisis menunjukan penurunan waktu tempuh rata- rata perjalanan per trip nya pada masing -masing proses yaitu penurunan sebesar $30 \%$ atau 1,01 menit/trip dari waktu rata- rata sebelumnya 3,37 menit/trip pada proses inbound dan pada proses outbound menurun sebesar $27.6 \%$ atau 0,92 menit/trip dari waktu sebelumnya sebesar 3,33menit/trip. Penentuan penempatan produk didasarkan atas nilai troughput yang paling tinggi di lokasikan paling dekat dengan titik lokasi I/O dan nilai troughput paling rendah di alokasikan paling jauh dari titik $\mathrm{I} / \mathrm{O}$, disamping itu juga ada beberapa aspek yang menjadi pertimbangan yaitu jenis produk, berat, dan karakteristik produk dalam penyimpanannya.

Pada penelitian ini penerapaan metode penyimpanan dedicate storage berlaku pada tipe penyimpanan gudang SPR (selective pallet racking), pada penelitian selanjutnya bisa di terapkan pada tipe penyimpanan gudang multideep atau combination type.

\section{Daftar Pustaka}

Abyadl, Q. (2017). Perbaikan Tata Letak Gudang Penyimpanan Dengan Mengunakan Metode Dedicated Storage (Studi Kasus: Pt. Eterindo Nusa Graha).

Bandyopadhyay, S. (2019). Facility Layout. In Production and Operations Analysis. 117157.

Ekren, B. Y., Sari, Z., \& Lerher, T. (2015). Warehouse Design under Class-Based Storage Policy of Shuttle-Based Storage and Retrieval System. IFAC-PapersOnLine, 48(3), 1152-1154.

Fumi, A., Scarabotti, L., \& Schiraldi, M. M. (2013). Minimizing Warehouse Space with a Dedicated Storage Policy. International Journal of Engineering Business Management, 5, 21.

Ginanjar, R. (2018). Usulan Perbaikan Tata Letak Gudang Penyimpanan Keramik Di PT. Alas Pusaka Menggunakan Metode Penyimpanan Dedicated Storage [Universitas Pasundan]. /

Hidayat, M. T. (2016). Usulan Perancangan Tata Letak Gudang Barang Jadi Dengan Menggunakan Metode Dedicated Storage Pada PT Keramik Diamond Industries [Airlangga University].

Moran, S. (2017a). Methods for Layout, Conception, and Development. In Process Plant Layout Elsevier, 75-83.

Moran, S. (2017b). Warehouse Storage. In Process Plant Layout Elsevier. 179-186..

Muharni, Y., Kulsum, \& Khoirunnisa, M. (2019). Warehouse Layout Designing of Slab Using Dedicated Storage and Particle Swarm Optimization. IOP Conference Series: 
Materials Science and Engineering, 532, 012003.

Muther, R., \& Webster, D. B. (2009). Plant Layout and Materials Handling. In Materials Handling Handbook (pp. 19-77). John Wiley \& Sons, Inc.

Retnowati, D., \& Fudhla, A. F. (2013). Re-Layout Fasilitas Produksi Industri Sheet Metal Working Berbasis Job Shop Dengan Pendekatan Linear. Prosiding Seminar Nasional Manajemen Teknologi XVII, 1-5.

Sentia, P. D., Suhendrianto, \& Rahman, A. (2017). Perancangan Tata Letak Gudang Penempatan Produk Menggunakan Metode Dedicated Storage. Facililities Planning (National Conference).

Septiani, W., Divia, G. A., \& Adisuwiryo, S. (2020). Warehouse Layout Designing of Cable Manufacturing Company using Dedicated Storage and Simulation Promodel. IOP Conference Series: Materials Science and Engineering, 847(1).

Warman, J. (2012). Manajemen Pergudangan Edisi Ketujuh. In Pustaka Sinar Harapan (edisi ke 7). Pustaka Sinar Harapan.

Wignjosoebroto, S. (2009). Tata Letak Pabrik dan Pemindahan Bahan (Edisi 3). Guna Widya.

Yang, P., Miao, L., Xue, Z., \& Ye, B. (2015). Variable neighborhood search heuristic for storage location assignment and storage/retrieval scheduling under shared storage in multi-shuttle automated storage/retrieval systems. Transportation Research Part E: Logistics and Transportation Review, 79, 164-177. 